formation, are discussed, together with their origins and transmission, in some instances by asymptomatic balanced carrier parents. Chromosome mosaicism and the occurrence of double trisomy, for example for number 21 and $X X Y$, are considered in detail. There follow a chapter on vital statistics in which mean survival age (about ten years or so in some statistics), causes of death and secular changes are discussed, and one on the aetiology of the anomaly. Here the different possible causes of Down's syndrome independent of maternal age are detailed and ideas are put forward about possible factors in the origin of the maternal-age dependent trisomy. Treatment and prevention, for example, by limiting conceptions after a certain maternal age, are considered. The genetic prognosis for those families in which an affected child is born is discussed, and the importance of chromosome studies of the patient and, if necessary, of the parents is emphasized.

The authors of this admirable book express the hope that their way of presenting the material may not only show the advances made but also stimulate further work. They cannot fail to succeed, because they have already achieved their aim of getting at least one reader both interested and stimulated.

P. E. Polani

\section{BIOLOGY AND STATISTICS}

\section{Biostatistics}

By Alvin E. Lewis. Pp. xi +227 . (New York: Reinhold Publishing Corporation; London: Chapman and Hall, Ltd., 1966.) $68 s$.

THIs is an elementary and essentially non-mathematical exposition of statistical ideas and methods, illustrated with examples mainly from biological sources; it is intended for "students in biology and medicine who have reached the stage where they are ready to judge data and to begin their own investigations and experiments". The standard topics of probability, random sampling, the normal distribution, the chi-squared distribution, tests of significance, and the analysis of variance are all presented, and there are brief chapters on quality control, sequential analysis and distribution-free methods. There is a summary and a good set of examples at the end of each chapter, and an excellent appendix of statistical tables.

It is extremely difficult to write a good statistical text with such a scope and aim, and Dr. Lewis only partially succeeds. Many of his approaches are good, such as the introduction of the $t$-test for paired observations before that for two separate samples. Others are less satisfactory, such as introducing the analysis of variance by way of the variance ratio test; this may mislead the beginner into regarding it as a method for studying heterogeneity of variances when the aim is to study heterogeneity of means. Some of the examples are a little strained ("spherical seeds") and at times the author gives the impression of not being quite at home either with biology or statistics.

IAN SUTHERLAND

\section{ORIENTATION STATISTICS}

\section{Structural Diagrams}

By Andrew B. Vistelius. Translated by R. Baker. Translation edited by N. L. Johnson and F. C. Phillips. Pp. $x i+178$. (London and Now York: Pergamon Press, 1966.) 80s, net.

THIS book was originally published in 1958, and deals with the treatment of orientation data from structural geology and petro-fabrics. These data are usually too complex to be tested statistically by the methods used by palaeomagnetists; and although tests have been proposed, none has been accepted for general use by structural geologists.

In such tests, including those of Vistelius, the results are plotted on a two-dimensional projection. Vistelius rejects the use of equal-angle and the equal-area projections in favour of an equal-interval projection. His arguments are not convincing and his choice increases the labour of testing. He warns against the use of polar instead of equatorial versions of projections, although they give identical plots of data. An introduction to probability theory and statistics is provided, but it is difficult to follow because too much statistical jargon is used in an attempt to be rigorous, and symbols change their meaning from equation to equation and even within paragraphs. Some of the tests proposed before 1958 are critically reviewed.

Vistelius then proposes four new tests which all involve determining the numbers of poles (data) falling in each of the cells of a net laid over the two-dimensional projection of the data. The $\chi^{2}$ and normal distributions are used to test for significant differences between the fre. quency distributions representing diagrams under test, and frequency distributions representing model random diagrams or other real diagrams. The tests include various objectionable features. The nets of cells are tailored to fit the data, which makes the tests partially subjective. The first test uses a false model of random distribution. The cells are so large that they tend to smooth out or randomize the data, thus decreasing the chance of detecting weak preferred orientations; yet the detection of weak preferred orientations is the most important task these tests can perform. Nevertheless, the second and fourth tests given by Vistelius are novel and could be useful if improved.

The book is poorly translated and badly edited. Typographical errors include " $n$ " in place of " $m$ " in Table $A 14$ and a mis-reference to an equation (page 45). Errors arising from a failure to understand the subject are more common and give rise to meaningless and even selfcontradictory sentences. Such errors include the literal translation of obscure Russian sentences; unjustified changes in the original punctuation; the omission of "not" in one sentence; and inversion of a mathematical substitution on page 44. Mis-translations include "position" instead of "attitude", and "fissure" instead of "joint". "Exposure", "cell", "thin section", and "cut" in "cut effect" are all translated as "section", causing considerable confusion. Equations 2.13 and 2.20 have been changed from the original without appropriate changes being made in the text.

The book is concerned solely with the statistical testing of diagrams. There is no discussion of sampling methods and neither discussion nor interpretation of the patterns of preferred orientation is shown by structural diagrams.

Derex FlinN

\section{OPTICAL ANALYSIS}

Treatise on Analytical Chemistry

Edited by I. M. Kolthoff and Philip J. Elving, with the assistance of Ernest B. Sandell. Part I: Theory and Practice, Vol. 6. Pp. xxiii $+3347-4246$. (New York and London: Interscience Publishers, a Division of John Wiley and Sons, 1965.) 175s.

THrs book deals with optical methods of analysis. The ten chapters cover a wide field, from emission spectroscopy to electron microscopy, and from flame photometry to neutron absorption.

A scientific critique of such a wide range of disciplines is clearly beyond the scope of a single reviewer; more is to be gained by taking the position of an interested reader seeking guidance. A random spot-checking within the various chapters for information on specific items gave me 